longer survival of HBV-ACLF. Additionally, ROC analysis showed that miR125b-5p(AUC $=0.814)$ had higher performance for survival prediction of HBV-ACLF as compared to miR-122 $(\mathrm{AUC}=0.804), \quad \mathrm{PTA}(\mathrm{AUC}=0.762) \quad$ MELD score $(\mathrm{AUC}=0.799)$ and TBil(AUC $=0.670$ ) alone; and predictive effectiveness of miR $125 \mathrm{~b}-5 \mathrm{p}$ was greatly increased by the combination of $\operatorname{miR} 122$ (AUC $=0.898$ ).

Conclusions The increasing of serum miR-125b-5p is associated severity of liver damage, and high serum miR-125b-5p may serve as a novel predictor of poor outcome of HBVACLF.

\section{IDDF2018-ABS-0106 TENOFOVIR ALAFENAMIDE (TAF) COMPARED WITH TENOFOVIR DISOPROXIL FUMARATE (TDF) IN PATIENTS WITH CHRONIC HBV: WEEK 96 EFFICACY AND SAFETY RESULTS IN CHINESE PATIENTS ENROLLED IN 2 GLOBAL PHASE 3 STUDIES}

${ }^{1}$ Henry Lik-Yuen Chan*, ${ }^{2}$ Wai Kay Seto, ${ }^{3}$ Scott Fung, ${ }^{4}$ Jinlin Hou, ${ }^{5}$ Calvin Pan, ${ }^{6}$ WanLong Chuang, ${ }^{7}$ Ting-Tsung Chang, ${ }^{8}$ Aric-Josun Hui ${ }^{8}$, Chi-Yi Chen, ${ }^{10}$ Tak Yin Owen Tsang, ${ }^{11}$ Jenny Yang, ${ }^{11}$ John Flaherty, ${ }^{11}$ Anuj Gaggar, ${ }^{11}$ Shuyuan Mo, ${ }^{12}$ Jia-Horng Kao. ${ }^{1}$ Department of Medicine and Therapeutics, Institute of Digestive Disease and State Key Laboratory of Digestive Disease, The Chinese University of Hong Kong, Hong Kong; ${ }^{2}$ Queen Mary hospital, Hong Kong; ${ }^{3}$ Toronto General Hospital, Toronto, ON, Canada; ${ }^{4}$ Nanfang Hospital, Guangzhou, China; ${ }^{5}$ New Discovery LLC, Flushing, NY, United States; ${ }^{6}$ Kaohsiung Medical University Hospital, Kaohsiung, Taiwan; 'National Cheng Kung University Hospital, Tainan, Taiwan; ${ }^{8}$ Alice Ho Miu Ling Nethersole Hospital, Hong Kong; ${ }^{9}$ Chiayi Christian Hospital, Chiayi, Taiwan; ${ }^{10}$ Princess Margaret Hospital, Hong Kong; ${ }^{11}$ Gilead Sciences, Foster City, CA, United States; ${ }^{12}$ National Taiwan University Hospital, Taipei, Taiwan

\subsection{6/gutjnl-2018-IDDFbestabstracts.19}

Background TAF, a novel prodrug of tenofovir, has demonstrated efficacy noninferior to that of TDF at Week 48 in patients with chronic HBV (CHB) with significantly reduced bone and renal effects. Here we evaluated the efficacy and safety of TAF vs TDF in the subset of patients of Chinese ethnicity enrolled in two overseas studies.

Methods In 2 Phase 3 studies, HBeAg-negative (Study 108) and HBeAg-positive (Study 110) CHB patients were randomised 2:1 to TAF $25 \mathrm{mg}$ QD or TDF $300 \mathrm{mg}$ QD and treated for 96 weeks. In this analysis, the efficacy (HBV DNA).

Results Of 1298 patients randomised and treated, 471 (36\%) were of Chinese ethnicity; 156 (TAF 97; TDF 59) and 315 (TAF 207; TDF 108) patients were HBeAg-negative and HBeAg-positive, respectively. For the TAF and TDF groups within each study, baseline characteristics of the study populations were generally similar. Key efficacy results at Weeks 48 and 96 are presented in the Table (table 1). In both HBeAgnegative and $\mathrm{HBeAg}$-positive patients of Chinese ethnicity, the antiviral efficacy of TAF was similar to that of TDF and results were comparable to those in the overall overseas population. Numerically higher percentages of patients treated with TAF achieved normalisation of serum ALT values and antiHBe seroconversion at Weeks 48 and 96. The safety of TAF and TDF, including changes in renal and bone parameters, were similar to results previously reported in the overall overseas population.

Conclusions In CHB patients of Chinese ethnicity, TAF $25 \mathrm{mg}$ showed similar antiviral efficacy to TDF $300 \mathrm{mg}$, with less change in bone and renal parameters. Results in this subgroup were comparable to those in the overall population.
Abstract IDDF2018-ABS-0106 Table 1 Efficacy Results at Week 48 and 96

\begin{tabular}{|c|c|c|c|c|}
\hline \multirow[b]{2}{*}{$\mathrm{n} / \mathrm{N}(\%)$} & \multicolumn{2}{|c|}{ HBeAg-negative } & \multicolumn{2}{|c|}{$\begin{array}{l}\text { HBeAg-positive Patients } \\
\text { (Study 110) }\end{array}$} \\
\hline & $\begin{array}{l}\text { TAF }(n= \\
97)\end{array}$ & $\begin{array}{l}\text { TDF }(n= \\
59)\end{array}$ & $\begin{array}{l}\text { TAF }(n= \\
\text { 207) }\end{array}$ & $\begin{array}{l}\text { TDF }(n= \\
108)\end{array}$ \\
\hline \multicolumn{5}{|l|}{ Week 48} \\
\hline HBV DNA $<29 \mathrm{IU} / \mathrm{mL}$ & $90(93 \%)$ & $55(93 \%)$ & $143(69 \%)$ & $76(70 \%)$ \\
\hline $\begin{array}{l}\text { ALT normalisation (AASLD } \\
\text { criteria) }^{\mathrm{a}}\end{array}$ & $\begin{array}{l}46 / 94 \\
(49 \%)\end{array}$ & $\begin{array}{l}18 / 59 \\
(31 \%)\end{array}$ & $\begin{array}{l}100 / 207 \\
(48 \%)\end{array}$ & $\begin{array}{l}39 / 108 \\
(36 \%)\end{array}$ \\
\hline HBeAg loss & $N A^{b}$ & NA & $\begin{array}{l}28 / 204 \\
(14 \%)\end{array}$ & $\begin{array}{l}11 / 103 \\
(11 \%)\end{array}$ \\
\hline HBeAg seroconversion & NA & NA & $\begin{array}{l}23 / 204 \\
(11 \%)\end{array}$ & $8 / 103(8 \%)$ \\
\hline \multicolumn{5}{|l|}{ Week 96} \\
\hline HBV DNA<29 IU/mL & $88(91 \%)$ & $57(97 \%)$ & $161(78 \%)$ & $86(80 \%)$ \\
\hline $\begin{array}{l}\text { ALT normalisation (AASLD } \\
\text { criteria) }^{a}\end{array}$ & $\begin{array}{l}46 / 94 \\
(49 \%)\end{array}$ & $\begin{array}{l}24 / 59 \\
(41 \%)\end{array}$ & $\begin{array}{l}119 / 207 \\
(57 \%)\end{array}$ & $\begin{array}{l}46 / 108 \\
(43 \%)\end{array}$ \\
\hline HBeAg loss & $N A^{b}$ & NA & $\begin{array}{l}55 / 204 \\
(27 \%)\end{array}$ & $\begin{array}{l}17 / 103 \\
(17 \%)\end{array}$ \\
\hline HBeAg seroconversion & NA & NA & $\begin{array}{l}47 / 204 \\
(23 \%)\end{array}$ & $\begin{array}{l}13 / 103 \\
(13 \%)\end{array}$ \\
\hline
\end{tabular}

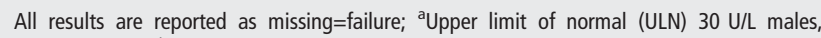
19 U/L females; ${ }^{b} \mathrm{NA}$, not applicable.

\section{IDDF2018-ABS-0113 THE SAFETY AND TOLERABILITY OF SOFI VEL/VOX FOR 8 OR 12 WEEKS IN $>1,000$ PATIENTS TREATED IN THE POLARIS-1, POLARIS-2, POLARIS-3, AND POLARIS-4 STUDIES: AN INTEGRATED ANALYSIS} ${ }^{6}$ Marc Bourliere, ${ }^{7}$ Tarik Asselah, ${ }^{8}$ Laurent Alric, ${ }^{9}$ Robert H Hyland, ${ }^{9}$ Luisa M Stamm, ${ }^{9} \mathrm{KC}$ Huang, ${ }^{9}$ Diana M Brainard, ${ }^{9}$ Chrstina SM Yip, Hai Cheng Huang ${ }^{9},{ }^{10}$ Mandana Khalili, ${ }^{11}$ Graham R Foster, ${ }^{12}$ Stuart C Gordon, ${ }^{13}$ Reddy K Rajender, ${ }^{14}$ Stefan Zeuzem, ${ }^{15}$ Ira M Jacobson, ${ }^{16}$ Curtis L Cooper, ${ }^{17}$ Alex J Thompson, ${ }^{18}$ Kris Kowdley, ${ }^{19}$ Eric Lawitz. ${ }^{1}$ Department of Gastroenterology, Hepatology and Endocrinology, Hannover Medical School, Hannove, Germany; ${ }^{2}$ Auckland Clinical Studies, Aucklan,, New Zealand; ${ }^{3}$ Centre Hospitalier de I'Universite de Montreal, Montreal, Canada; ${ }^{4}$ Alfred Hospital, Melbourne, Australia; ${ }^{5}$ Northwestern University, Chicago, USA; ${ }^{6}$ Hospital Saint Joseph, Marseille, France; ${ }^{7}$ Service d'Hepatologie, Hopital Beaujon, Universite Paris Diderot, Clichy, France; ${ }^{8}$ Internal MedecineDigestive Department, CHU Purpan, URM 152, Toulouse 3 University, Toulouse, France; ${ }^{9}$ Gilead Sciences, Inc., Foster City, CA, USA; ${ }^{10}$ University of California San Franciso, San Francisco, USA; ${ }^{11}$ Royal London Hospital, London, UK; ${ }^{12}$ Henry Ford Health System, Detroit, USA; ${ }^{13}$ University of Pennsylvania, Philadelphi, USA; ${ }^{14}$ Johann Wolfgang Goethe University Medical Center, Frankfurt, Germany; ${ }^{15}$ Department of Medicine, Mount Sinai Beth Israel, New York, USA; ${ }^{16}$ Ottawa Hospital Research Institute, Ottawa, Canada; ${ }^{17}$ Department of Gastroenterology, St. Vincent's Hospital, Melbourne, Australia; ${ }^{18}$ Swedish Medical Center, Seattle, USA; ${ }^{19}$ Texas Liver Institute, University of Texas Health Science Center, San Antonio, USA

\subsection{6/gutjnl-2018-IDDFbestabstracts.20}

Background The once-daily fixed-dose combination tablet of sofosbuvir/velpatasvir/voxilaprevir (SOF/VEL/VOX) was evaluated for the treatment of genotype 1-6 HCV infection in four phase 3 studies in patients with and without compensated cirrhosis. This analysis describes the safety of SOF/VEL/VOX across 4 Phase 3 studies.

Methods Treatment-emergent adverse events (AEs) and laboratory abnormalities were assessed in patients who received SOF/VEL/VOX or placebo for 12 weeks (POLARIS-1), SOF/ VEL/VOX or SOF/VEL for 12 weeks (POLARIS-4), or SOF/ 